\title{
Decisiones informadas en el rastreo de cáncer de mama
}

\author{
Informed decisions in breast cáncer screening
}

Hersch J y Col, Lancet 2015 385:1642-52.

\section{Objetivos}

Investigar si la inclusión de información acerca de sobrediagnóstico en los folletos que informan sobre el rastreo de cáncer de mama mejora las decisiones vinculadas al rastreo de dicha condición clínica.

\section{Diseño, lugar y pacientes}

Ensayo clínico aleatorizado con dos grupos paralelos, realizado en Australia. Se extrajo del registro electoral, información de mujeres entre 48 y 50 años en forma aleatoria $(n=2.647)$. Fueron excluidas quienes habían realizado una mamografía durante los últimos dos años, quienes tenían historia familiar o personal de cáncer de mama, y quienes no hablaban inglés en forma fluida. Finalmente, 879 mujeres fueron aleatorizadas a los dos grupos en forma computarizada.

\section{Intervención}

Luego de la entrevista de elegibilidad, las mujeres de ambos grupos recibieron versiones diferentes de un folleto con información sobre el rastreo de cáncer de mama. Ambas versiones incluían información sobre las muertes evitadas por el rastreo y sobre el riesgo de resultados falsamente positivos, pero sólo el folleto del grupo intervención abordaba la problemática del sobrediagnóstico. Luego de una a cuatro semanas se realizaron entrevistas de seguimiento.

\section{Medición de resultados principales}

Fue considerado resultado principal la toma de una decisión informada sobre el rastreo de cáncer de mama, basada en el conocimiento, las actitudes y las intenciones de la usuaria y evaluada en forma dicotómica. El conocimiento fue evaluado a través de preguntas previamente desarrolladas, las actitudes mediante una escala de seis ítems previamente validada, y las intenciones, a través de una pregunta con cinco opciones. Se consideró que una mujer había tomado una decisión informada si tenía el conocimiento adecuado, y si sus actitudes e intenciones eran consistentes.

\section{Resultados}

De las 879 mujeres asignadas a ambos grupos, 838 (95\%) completaron la entrevista telefónica de seguimiento. Quienes no completaron la entrevista referida a aspectos actitudinales fueron excluidas del análisis del resultado principal. Tanto las características sociodemográficas, como las actitudes, las intenciones y el conocimiento respecto del rastreo, fueron similares en ambos grupos; y el $90 \%$ de las mujeres comunicó que realizaría rastreo en los próximos años. Luego de la intervención y de las entrevistas posteriores se obtuvieron los siguientes resultados (Ver tabla 1). No hubo diferencias en relación al nivel de ansiedad entre ambos grupos.

Tabla 1: Porcentaje de toma de decisión informada respecto del rastreo de cáncer de mama.

\begin{tabular}{|c|c|c|c|c|c|}
\hline & \multicolumn{2}{|c|}{ Grupo } & \multirow{2}{*}{$\begin{array}{c}\text { Diferencia } \\
\text { (IC95\%) }\end{array}$} & \multirow[t]{2}{*}{ p } \\
\hline & & Intervención & Control & & \\
\hline \multicolumn{2}{|c|}{ Decisión informada } & $99 / 409(24 \%)$ & $63 / 408(15 \%)$ & $8,8(3,3$ a 14,2$)$ & 0,0017 \\
\hline \multirow{3}{*}{$\begin{array}{l}\text { Intenciones } \\
\text { acerca } \\
\text { del rastreo }\end{array}$} & Con intención de rastreo & $308(74 \%)$ & $363(87 \%)$ & $-13,1(-18,5$ a -7.8$)$ & $<0,0001$ \\
\hline & Indecisas & $69(16 \%)$ & $30(7 \%)$ & $9,3(2,5$ a 16,1$)$ & $<0,0001$ \\
\hline & Poca o ninguna intención & $42(10 \%)$ & $26(6 \%)$ & $3,8(-3$ a 10,6$)$ & $<0,0001$ \\
\hline
\end{tabular}

\section{Conclusiones}

Los hallazgos de este estudio determinan que las herramientas para la ayuda de toma de decisiones que incluyen información acerca de sobrediagnóstico, aumentan el conocimiento general y permiten a las mujeres realizar una decisión informada respecto del rastreo de cáncer de mama, sin que exista eviden- cia de que esta información aumente la ansiedad o las preocupaciones de las usuarias. Cabe destacar que no existe consenso sobre lo que significa estar objetivamente informado, y que al margen de que en este estudio se explican las definiciones consideradas, más estudios de investigación se tendrían que hacer al respecto.

\section{Comentario}

Se define sobrediagnóstico o sobredetección al diagnóstico de una condición clínica que de no haber sido "diagnosticada", no habría causado síntomas en la vida de esa persona. Este diagnóstico suele conducir a la realización de tratamientos (sobretratamiento) que pueden resultar en daños físicos y/o psíquicos. Es necesario destacar la importancia de este trabajo, ya que posiciona el concepto de sobrediagnóstico como un punto a tener en cuenta a la hora de tomar decisiones. Y más aún porque esto se plantea desde el punto de vista de las pacientes/usuarias, y no solo desde la visión de los profesionales de la salud. Enfocándonos en el estudio, uno de los principales cuestionamientos, es la abstracción de los parámetros a medir.

\section{Conclusión de la comentadora}

La definición de decisión informada puede ser muy variable, y definitivamente no es un concepto estático, aunque no cabe duda que es influenciada por la información que recibimos. Pero: ¿qué pasa con las emociones? Como comenta Lisa Rosenbaum': “...es en parte porque nuestra percepción de riesgo es tan influenciada por nuestras cambiantes emociones que consultamos a expertos para realizar análisis costo-beneficio...". Y este es un punto que no puede ignorarse, ya que un concepto complejo como el de sobrediagnóstico se mezcla con la nueva realidad de que existe incertidumbre respecto de la "recomendación" de realizar rastreo antes tan mandatoria. Esto plantea un desafío para los profesionales de la salud, ya que obliga al desarrollo y la validación de nuevas formas de comunicación.

Maria Victoria Ruiz Yanzi [ Servicio Medicina Familiar y Comunitaria del Hospital Italiano de Buenos Aires. mariav.ruiz@hospitalitaliano.org.ar]

Ruiz Yanzi V. Decisiones informadas en el rastreo de cáncer de mama. Evid Act Pract Ambul. 2016;19(2):44. Abr-Jun. Comentado de: Hersch J, y col. Use of a decision aid including information on overdetection to support informed choice about breast cancer screening: a randomised controlled trial. Lancet. 2015;385(9978):1642-52. PMID: 25701273

Referencia

1. Rosenbaum L. Invisible Risks, Emotional Choices-Mamography and Medical Decision Making, N Engl J Med.2014.371:16 